\title{
Novel method for quantification of individual free fatty acids in milk using an in-solution derivatisation approach and gas chromatography-mass spectrometry
}

\author{
Bashar Amer, Caroline Nebel, Hanne C. Bertram, Grith Mortensen, Kjeld Hermansen, Trine K. Dalsgaard
}

Liberation of short chain fatty acids (C4-C12) by milk or bacterial lipases is one of the main causes of the rancid off-flavour in milk and milk products (IDF, 1991). The implementation of automatic milking systems (AMS) in many farms with larger herds increases the need for quantification of FFAs (Klungel, Slaghuis, \& Hogeveen, 2000), as the level of FFAs is higher in herds with AMS systems compared with milking in parlour systems (Abeni, Degano, Calza, Giangiacomo, \& Pirlo, 2005).

Another factor that affects the level of FFAs in milk is the microbial lipases, which are produced by psychrotrophic bacteria. These bacteria catalyse milk fat lipolysis (Antonelli, Curini, Scricciolo, \& Vinci, 2002), and bacteria lipases have been pointed out to be the major future problem (Deeth, 2006). Bacteria lipases may be less of a problem in the Western world, as hygiene issues are carefully monitored. However, reliable methods are required, as the production of milk is still increasing in parts of the world where inferior hygiene remains an important issue.

Several analytical methods are available to determine the level of FFAs in dairy products. However, most of these methods suffer from their inability to recover all FFAs. One of the analytical methods described is the Bureau of Dairy Industries (BDI) method that recovers only about $50-70 \%$ of the FFAs in milk (IDF, 1991).

The present method describes a simple and rapid in-solution derivatisation of FFAs in milk into their ethyl esters with ethyl chloroformate (ECF) without any work-up steps involving evaporation of solvent or FFA extraction before derivatisation where short chain free fatty acids (SCFFAs) could be lost. A subsequent analysis of the ethyl esters with gas chromatography-mass spectrometry ensures a specific, sensitive, precise and accurate method for determination of FFAs in milk.

Abeni, F., Degano, L., Calza, F., Giangiacomo, R., \& Pirlo, G. (2005). Milk quality and automatic milking: fat globule size, natural creaming, and lipolysis. Journal of Dairy Science, 88, 3519-3529.

Antonelli, M. L., Curini, R., Scricciolo, D., \& Vinci, G. (2002). Determination of free fatty acids and lipase activity in milk: quality and storage markers. Talanta, 58, 561-568.

Deeth, H. C., Fitz-Gerald, C. H., \& Snow, A. J. (1983). A gas chromatographic method for the quantitative determination of free fatty acids in milk and milk products. New Zealand Journal of Dairy Science and Technology, 18, 13-20.

IDF. (1991). Determination of free fatty acids in milk and milk products. IDF bulletin No. 265. Brussels, Belgium: International Dairy Federation.

Klungel, G. H., Slaghuis, B. A., \& Hogeveen, H. (2000). The effect of the introduction of automatic milking systems on milk quality. Journal of Dairy Science, 83, 1998- 2003. 